\title{
Effects of the Atmosphere and Substrate on the Crystallization of PLZT Thin Films
}

\author{
A.Z. Simões ${ }^{\mathrm{a}}$, A.H.M. Gonzalez ${ }^{\mathrm{a}}$,M.A. Zaghete ${ }^{\mathrm{a}}$, J.A. Varela ${ }^{\mathrm{a}}$, \\ B.D. Stojanovic ${ }^{\mathrm{b}}$ \\ ${ }^{a}$ Instituto de Química, Departamento de Físico-Química, UNESP, \\ 14801-970 Araraquara - SP, Brazil \\ ${ }^{\mathrm{b}}$ Center for Multidisciplinary Studies, University of Belgrade, Belgrade, Yugoslavia
}

Received: December 20, 1999; Revised: July 3, 2000

\begin{abstract}
Lead lanthanum zirconate titanate [PLZT (9/65/35)] thin films were prepared by dip-coating on $\mathrm{Si}$ (100) or Si/Ti/Pt (100) substrates using a polymeric precursor solution and annealed at $650{ }^{\circ} \mathrm{C}$ for $3 \mathrm{~h}$. Perovskite phase formation of the PLZT thin films and microstructure were analysed using XRD and SEM. Effects of Si (100), Si/Ti/Pt (100) substrates and atmosphere on crystallization of PLZT thin films were studied. Films deposited on platinum coated silicon (100) show a heterogeneous surface with presence of bubbles. Otherwise, the PLZT (9/65/35) thin films deposited on silicon (100) substrate shows a more uniform surface after annealing in oxygen atmosphere.
\end{abstract}

Keywords: PLZT, Pechini method, dip-coating, crystallization

\section{Introduction}

The ferroelectric PLZT thin films have been used for ferroelectric random acess memory (FRAM), waveguide modulator, display, and other electrooptic devices ${ }^{1-8}$. Due to the high temperatures required for the formation of the ferroelectric perovskite phase and the complex stoichiometry, the production of PLZT thin film has not proved easy and, at present, a wide range of thin films synthesis techniques, such as MOCVD, sol-gel, RF magnetron and ion beam sputtering, and laser ablation are subject to intensive research ${ }^{9}$. One of the method recently applied to obtain thin films is the polymeric organic solution based on Pechini's method. The thin films of $\left(\mathrm{LiNbO}_{3}\right.$, $\mathrm{SrTiO}_{3}$ and $\mathrm{SrBi}_{2} \mathrm{Nb}_{2} \mathrm{O}_{9}$ ) obtained from Pechini's method have a good morphologies and structural characteristics, which are very important to optical properties ${ }^{10-12}$. This method has also been used to obtain PLZT powders with good stoichiometry control and high surface area ${ }^{13}$.

It has been reported that the crystallization process is affected by variable such as composition ( $\mathrm{Zr} / \mathrm{Ti}$ ratio), substrate, annealing temperature, atmosphere, drying condition $^{3-8}$. It was noticed that the oxygen atmosphere has a prominent influence on crystallization process of PLZT.

e-mail: alexsimo@iq.unesp.br
The crystallization process developed at a lower temperature results in a Ti-rich PLZT compositions and at higher temperatures results in a Zr-rich PLZT compositions ${ }^{14}$. Films annealed at higher temperatures can lead to a secondary phase $\mathrm{Pb}$-deficient, $\mathrm{Pb}(\mathrm{Ti}, \mathrm{Zr})_{3} \mathrm{O}_{7}$. Higher temperatures also favors the interfacial reactions with silicon-based substrates. Much effort has been expended on the processing of PLZT to eliminate the undesirable phase on the composition of thin films. Thus, the control of atmosphere and temperature are critical factors in the development of single-phase perovskite material.

The crystallographic orientation of thin film affects significantly the material properties and it's possible to modify the orientation of the film by controlling the orientation of the underlying layer, film thickness and atmosphere flow. In general, PZT and PLZT films deposited on silicon and platinum coated silicon substrates have (111) preferred orientation because in this plane the interatomic distances of the material and substrate are very closed.

The effect of oxygen atmosphere on the crystallization of the PLZT phase is to prevent the volatility of PbO, control the stoichiometry and improve the electric properties of the film ${ }^{15}$. 
The ferroelectric PLZT (X/65/35) with La content in the interval of $8-10 \mathrm{~mol} \%$ has been extensively studied because of the high transparency at visible light and its large electrooptic effect ${ }^{16-20}$.

Having this in mind, the main objective of this work is to study, the PLZT thin films with the chemical formula $\mathrm{Pb}_{0.91} \mathrm{La}_{0.09}\left(\mathrm{Zr}_{0.65} \mathrm{Ti}_{0.35}\right) \mathrm{O}_{3}$ obtained by dip-coating from a citrate organic solution. The effects of substrates and atmosphere on crystallization and morphology of PLZT $(9 / 65 / 35)$ thin films were analysed ${ }^{21}$.

\section{Experimental}

In this study the PLZT composition named (9/65/35) was used. Zirconium n-propoxide (Aldrich), titanium isopropoxide (Hulls AG), hydrated lanthanum carbonate (Aldrich) and lead acetate (Merck) were used as raw materials. The precursors solutions of zirconium, titanium, lanthanum and lead were prepared by adding the raw materials in ethylene glycol and citric acid during heating and stirring at $90{ }^{\circ} \mathrm{C}$. Appropriate quantities of solutions of $\mathrm{Zr}, \mathrm{Ti}, \mathrm{Pb}$ and La were mixed and homogeneized by stirring at $90^{\circ} \mathrm{C}$. The viscosity of the solution was adjusted at $40 \mathrm{cP}$ by addition of water and measured by Brookfield viscosimeter. The films were deposited by dip-coating process. The withdrawal speed of substrate from the solution was adjusted at $5 \mathrm{~mm} / \mathrm{min}$, and the heating rate for crystallization of PLZT thin films was adjusted at $5{ }^{\circ} \mathrm{C} / \mathrm{min}$. These conditions were used to obtain homogeneous and crack-free films.

PLZT films obtained from polymeric solution were deposited on silicon (100) and platinum coated silicon (100) substrates and pre-annealed at $90^{\circ} \mathrm{C}$ in a hot plate for polyesterification, elimination of water and the excess of ethylene glycol. Films with 1, 2 and 3 layers were prepared. For each single layer thermal treatment was perfomed at $650{ }^{\circ} \mathrm{C}$. To study the effect of atmosphere on the crystallization, the films were annealed in static air and dynamic oxygen flow of $50 \mathrm{~mL} / \mathrm{min}$.

Phases analysis of the films was performed at room temperature using X-ray diffractometry (XRD). The morphology of the annealed films was studied using scanning electron microscopy (SEM) while the roughness was measured by atomic force microscopy (AFM). PLZT films surface were analysed without any cover or special preparation and with incidence of secondary electrons.

\section{Results and Discussion}

The X-ray diffraction data obtained from PLZT thin films deposited on silicon (100) substrates are shown in Fig. 1 . The PLZT films were prepared from solution with viscosity $40 \mathrm{cP}(1,2$ and 3 layers $)$ and annealed at $650{ }^{\circ} \mathrm{C}$ for
$3 \mathrm{~h}$ in static air and oxygen flow atmosphere. The peaks located at $2 \theta=22^{\circ}, 31.3^{\circ}, 38^{\circ}$ and $44.78^{\circ}$ corresponds to polycrystalline PLZT phase for films annealed in air (Fig. 1a). It was also observed an increase in the intensities of the peak with increasing of film thickness. The pyrochlore phase was only observed for films with three layers (Fig. 1a curve (c)). It can be concluded that the air atmosphere favored the crystallization of polycrystalline PLZT phase.

Films annealed in oxygen atmosphere showed some preferential orientation on the direction (111) and (200) of PLZT phase, as well as a presence of small amount of pyrochlore phase. It is indicates that the presence of pyrochlore phase does not prevent the preferential orientation of PLZT phase during annealing.

These results pointed that the use of oxygen atmosphere during annealing has a prominent influence on formation of PLZT crystalline phase. Independently of the number of deposited layers, the presence of oxygen favored the crystallization of PLZT phase with preferential orientation on directions (111) and (200), (Fig. 1b).
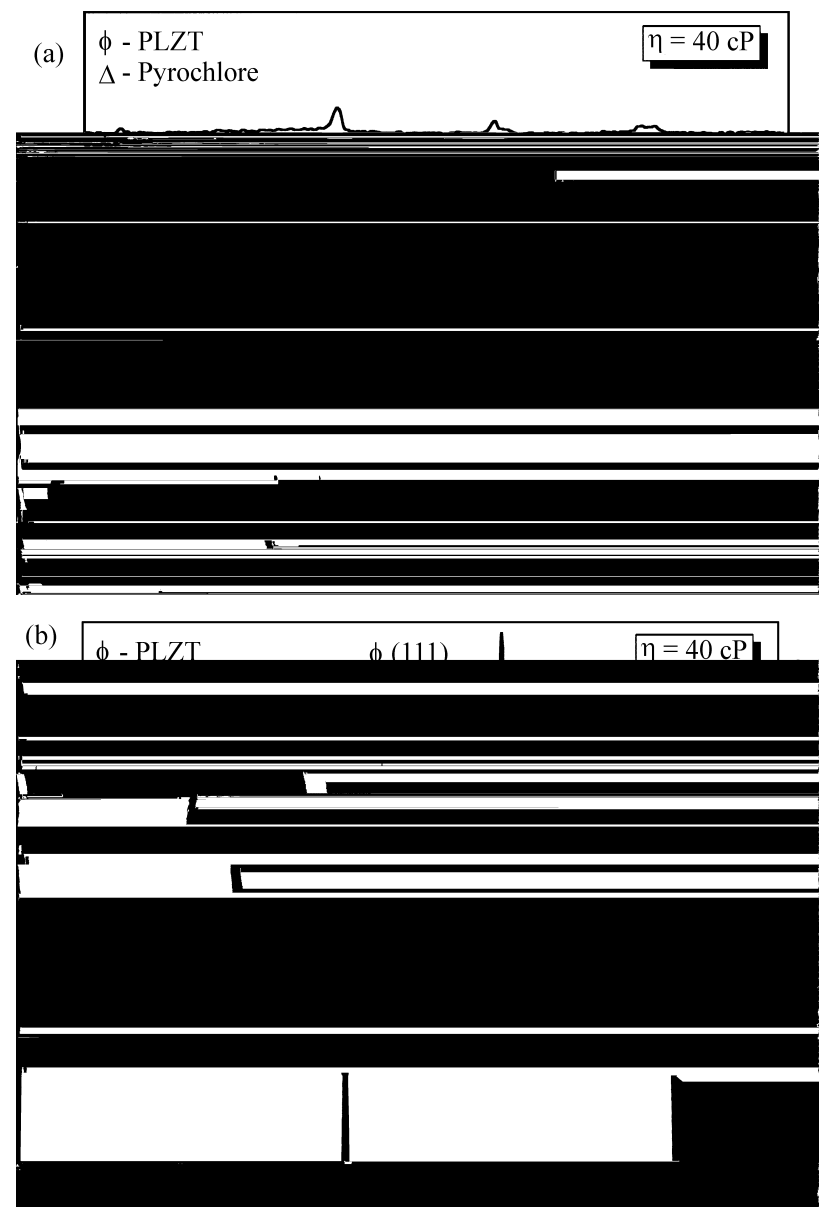

Figure 1. XRD patterns of PLZT films $(\eta=40 \mathrm{cP})$ deposited on $\mathrm{Si}$ (100) substrate and annealed at $650{ }^{\circ} \mathrm{C}$ for $3 \mathrm{~h}$ in differents atmospheres: (a) air and (b) oxygen. 
The oxygen flow promotes the decomposition of the organic material that is an exothermic reaction. Increasing the speed decomposition, the amount of energy also favor the crystallization from substrate surface. The preferential orientation is more evident for the PLZT films with one layer than for two or three layers (Fig. 1b). This results suggests that the crystallization process starts from the surface of substrate which has oriented planes with lower energy for crystallization of PLZT phase.

The X-ray diffraction data obtained from PLZT thin films deposited on platinum coated silicon (100) substrates are shown in Fig. 2. The PLZT films were prepared from solutions with viscosity $40 \mathrm{cP}(1,2$ and 3 layers) and annealed at $650{ }^{\circ} \mathrm{C}$ for $3 \mathrm{~h}$ in static air and oxygen atmosphere. Characteristic peak for platinum coated silicon (100) substrates was observed in the range of $38^{\circ}<2 \theta<41^{\circ}$.

The peak related to polycrystalline PLZT phase at $2 \theta=31.3^{\circ}$ was observed to films annealed in air and oxygen, Figs. $2 \mathrm{a}$ and $2 \mathrm{~b}$. Films with three layers annealed in oxygen atmosphere showed the main peaks of PLZT phase at $2 \theta=22^{\circ}$ and $44.78^{\circ}$ (Fig. $2 \mathrm{~b}$ curve (c)). A peak at $2 \theta=$ $46^{\circ}$ pointed to a reaction between platinum, titanium and formation of intermetallic $\mathrm{Pt}_{3} \mathrm{Ti}$ phase. This phase is favored in an oxygen atmosphere (Fig. 2b curve (a) and (c)). It can be noticed (Fig. 2b) that the presence of secondary phase $\mathrm{Pt}_{3} \mathrm{Ti}$ formed in the interface PLZT-film inhibits the PLZT growth in some preferential orientation. The Fig 2c. shows the results of the X-ray diffraction obtained from PLZT thin films deposited on platinum coated silicon (100) substrates with low angle where preferential orientation is not observed.

The morphology of film surfaces obtained for two layers deposited on silicon (100) and platinum coated silicon (100) substrates annealed at $650{ }^{\circ} \mathrm{C}$ for $3 \mathrm{~h}$ are shown in Figs. 3 and 4. The surfaces of films are homogeneous and uniform, (Figs. 3a and 3b). Crack-free thin films were obtained on platinum coated silicon (100) substrate. Otherwise, it can be noticed on the surface of films some white regions (Figs. 4a and 4b). These defects were apparently caused by differences in thermal properties (thermal expansion coefficient and heat capacity) of platinum $\left(910^{-6}{ }^{\circ} \mathrm{C}^{-1}\right.$

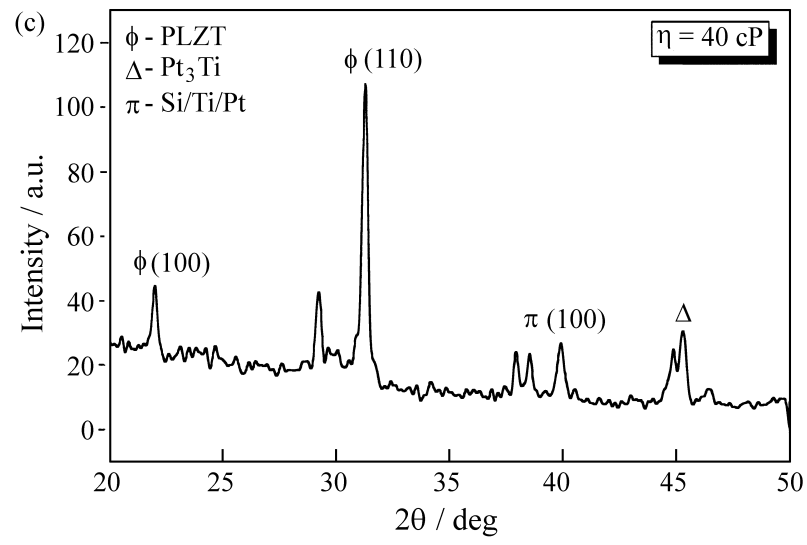

Figure 2. XRD patterns of PLZT films ( 

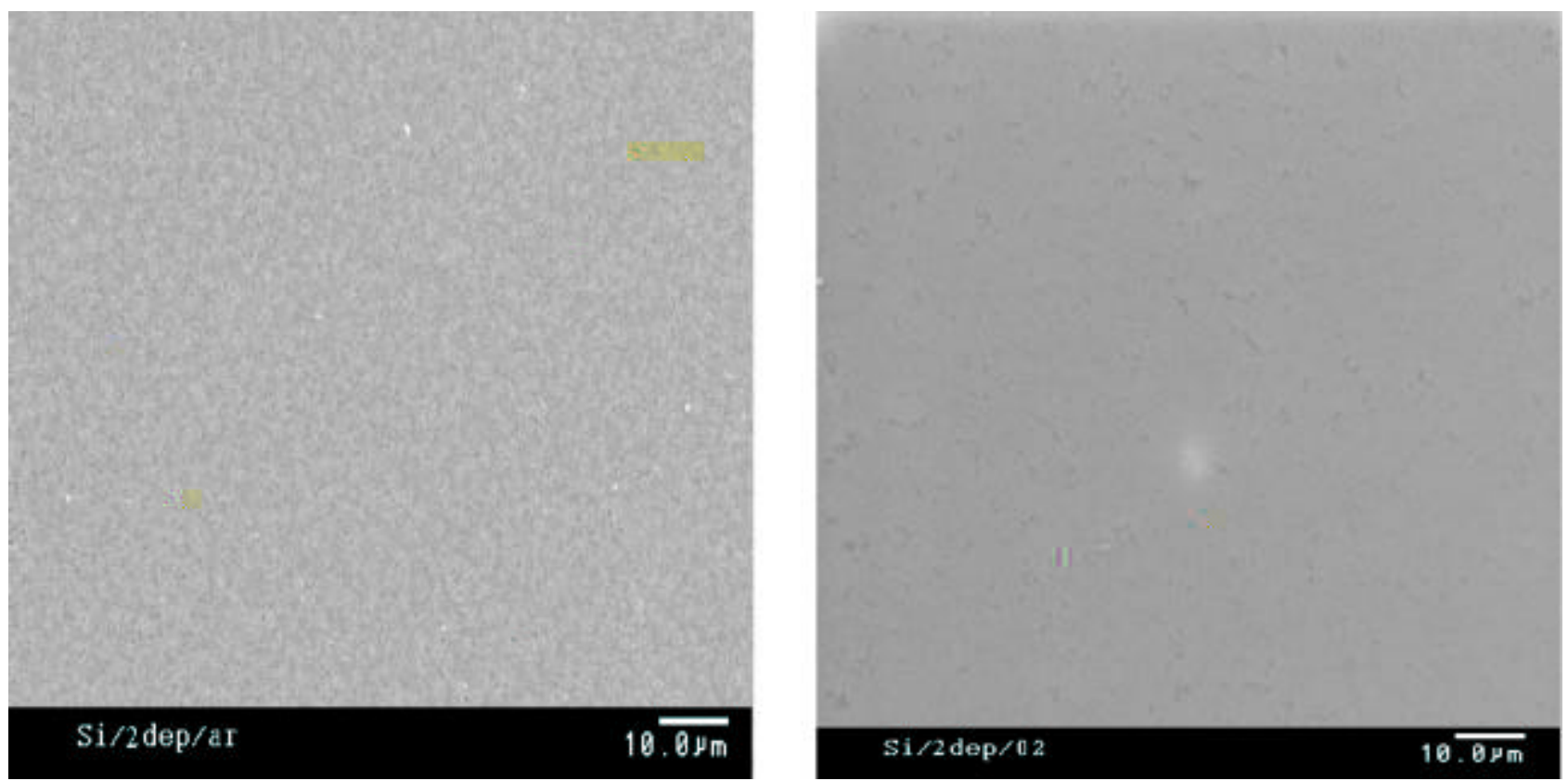

Figure 3. SEM micrographs of PLZT film surfaces $(\eta=40 \mathrm{cP})$ deposited on $\mathrm{Si}(100)$ substrate with speed of $5 \mathrm{~mm} / \mathrm{min}$, heating rate of $5{ }^{\circ} \mathrm{C} / \mathrm{min}$ and annealed at $650{ }^{\circ} \mathrm{C}$ for $3 \mathrm{~h}$ at differents atmospheres: (a) air and (b) oxygen.

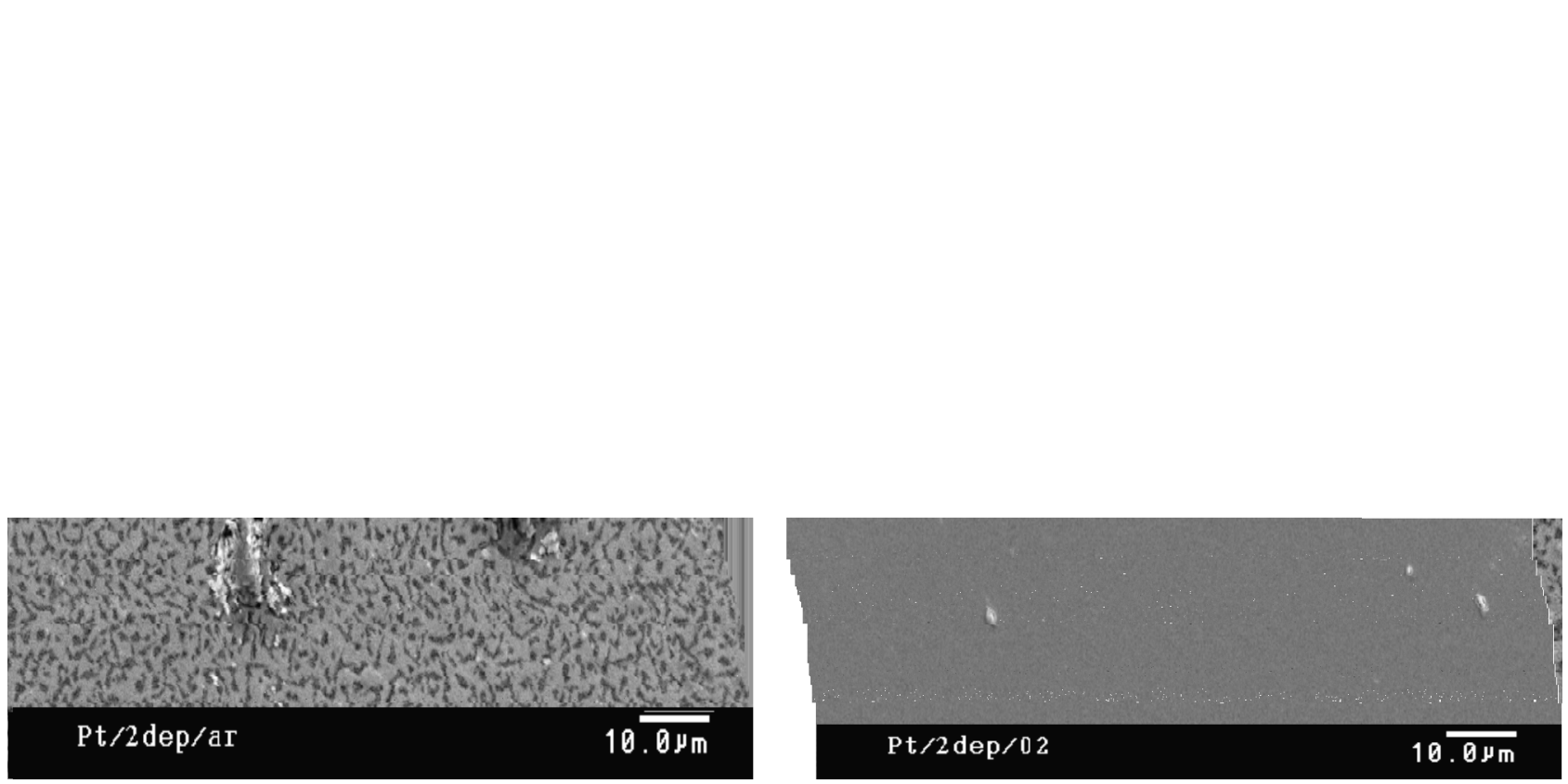

Figure 4. SEM micrographs of PLZT film surfaces $(\eta=40 \mathrm{cP})$ deposited on $\mathrm{Si} / \mathrm{Ti} / \mathrm{Pt}(100)$ substrate with speed of $5 \mathrm{~mm} / \mathrm{min}$, heating rate of $5{ }^{\circ} \mathrm{C} / \mathrm{min}$ and annealed at $650{ }^{\circ} \mathrm{C}$ for $3 \mathrm{~h}$ at differents atmospheres: (a) air and (b) oxygen.

and $\left.0.1338 \mathrm{~J} / \mathrm{g}{ }^{\circ} \mathrm{C}\right)$ and PLZT film $\left(5.610^{-6}{ }^{\circ} \mathrm{C}^{-1}\right.$ and $0.1045 \mathrm{~J} / \mathrm{g}{ }^{\circ} \mathrm{C}$ ). These lead to a higher volatilization rate of organic materials and of the species with low vaporization temperature, like $\mathrm{PbO}$. Contrary to that, for the silicon (100) substrate the thermal expansion coefficient and heat capacity $\left(3.10^{-6}{ }^{\circ} \mathrm{C}^{-1}\right.$ and $\left.0.0711 \mathrm{~J} / \mathrm{g}{ }^{\circ} \mathrm{C}\right)$ are lower than for PLZT film. Thus, it is able to form a homogeneous and regular surface of films.
Topography of the films thermally treated in air and oxygen atmosphere are shown in Fig. 5. It is observed that independently of substrate used, films annealed in oxygen atmosphere show a more homogeneous surface compared to the films annealed in air. This is due to the small thickness obtained for the films thermally treated in oxygen atmosphere favoring the redistribution of grains during annealing. 


\section{Conclusions}

PLZT thin films deposited on silicon (100) and platinum coated silicon (100) substrates and annealed in air atmosphere are polycrystalline. Films deposited on silicon (100) substrate and annealed in oxygen atmosphere showed some preferential orientation on the (111) and (200) direction. Films deposited on platinum coated silicon (100) substrate showed the presence of $\mathrm{Pt}_{3} \mathrm{Ti}$ phase as a result of reaction between platinum and titanium in oxygen atmosphere. The best morphologic characteristics are obtained for thin films deposited on $\mathrm{Si}$ (100) substrate and annealed in oxygen atmosphere.

\section{Acknowledgements}

The authors acknowledge the Brazilian Agencies 
12.Zanetti, S.M.; Leite, E.R.; Longo, E.; Varela, J.A. Appl. Organometal. Chem, v. 13, p. 1, 1999.

13. Zaghette, M.A. Doctor Thesis, Materials Engineering Department, UFSCar, Brazil, 1994.

14.Kwok, C.K.; Desu, S.B.; Low Temperature Perovskite Formation of Lead Zirconate Titanate Thin Films by a Seeding Process, J. Mater. Res, v. 8, n. 2, p. 339-44, 1993.

15. Petersen, G.A.; Zou, L.C.; VanBuren, W.M.; Boyer, L.L.; Mcneil, J.R. Proc. Mater. Res. Soc, Spr. Meet., San Francisco, CA, v. 200, p.127, 1990.

16. Wegner, A.B.; Brucck S.R.J.; Wu, A.Y. Ferroelectrics, v. 116, p. 195, 1991.
17. Kawaguchi, T.; Adachi, H.; Setsune, K.; Yamazaki, O.; Wasa, K. Appl. Opt, v. 23, p. 2178, 1984.

18. Paz de Araujo, C.A.; Memillan, L.D.; Melnick, B.M.; Cuchiaro J.D.; Scott, J.F. Ferroelectrics, v. 104, p. 241, 1990.

19. Okuyama, M.; Usuki, T.; Hamakawa, Y.; Nakagawa, T. Appl. Phys, v. 21, p. 339, 1980.

20. Carim, A.H.; Tuttle, B.A.; Doughty, D.H.; Martinz, S.L. J. Am. Ceram. Soc, v. 74, p. 1455, 1991.

21. Dungan, R.H.; Snow, G.S. Amer. Cer. Soc. Bull, v. 56, p. $781,1977$. 